\title{
An Anatomical Variation of Terminal Branches of the Thoracoacromial Artery - Case Report
}

\author{
Loránd Kocsis', Mihai-luliu Harșa1, Lóránd Dénes², Zsuzsánna Pap² \\ 1 Student, "George Emil Palade" University of Medicine, Pharmacy, Science and Technology, Târgu Mureş, Romania \\ 2 Department of Anatomy and Embryology, "George Emil Palade" University of Medicine, Pharmacy, Science and Technology, Târgu \\ Mureş, Romania
}

\section{CORRESPONDENCE}

\section{Mihai-luliu Harșa}

Str. Gheorghe Marinescu nr. 38

540139 Târgu Mureș, Romania

Tel: +40 265215551

E-mail: harsaiuliu@gmail.com

\section{ARTICLE HISTORY}

Received: July 6, 2020

Accepted: September 3, 2020
Loránd Kocsis • Str. Gheorghe Marinescu nr 38, 540139 Târgu Mureș, Romania. Tel: +40 265215 551, E-mail: kocsisfl@gmail.com

Lóránd Dénes • Str. Gheorghe Marinescu nr. 38 540139 Târgu Mureș, Romania, Tel: +40 265215 551, E-mail: deneslorand@gmail.com

Zsuzsanna Pap • Str. Gheorghe Marinescu nr. 38 540139 Târgu Mureș, Romania, +40 265215551

E-mail: zsuzsanna.pap@umfst.ro

\begin{abstract}
Introduction: Mapping the branching patterns of the thoracoacromial artery has a particular practical importance. Familiarity with the different anatomical variations is essential for successful surgical procedures in the anterior shoulder region. Case presentation: We present an unusual anatomical variant observed during the dissection of a cadaver at the Department of Anatomy and Embryology of the "George Emil Palade" University of Medicine, Pharmacy, Science and Technology of Târgu Mureş, Romania. According to the classical description, the thoracoacromial artery originates from the second part of the axillary artery, but we observed an unusual branching variation: the thoracoacromial artery provided a subscapular branch right after its origin, then it split into a pectoral branch, the lateral thoracic artery, and a common trunk that gave a second pectoral branch and a deltoid-acromial branch. The clavicular branch was missing. Conclusions: The case we presented demonstrates that there are anatomical variations of the axillary artery system that are partially or entirely different from the classical descriptions. Our study describes a variation of the thoracoacromial artery that has not been reported so far.
\end{abstract}

Keywords: thoracoacromial artery, lateral thoracic artery, terminal branches, anatomical variations

\section{INTRODUCTION}

Blood supply of the shoulder region is provided by the branches of the axillary artery (AA). The AA continues the subclavian artery and extends from the first rib to the inferior margin of the $\mathrm{m}$. teres major. In the anterior region, the AA is covered by the $\mathrm{m}$. pectoralis minor, from where it divides into three parts: the first part is proximal to m. pectoralis minor, the second part is behind the muscle, and the third part is located distal to the muscle. According to the classical description, the first segment provides the superior thoracic artery, the second part provides the thoracoacromial artery (ATA) and the lateral thoracic artery (ATL), and the third part gives off the subscapular artery (AS), and the anterior and posterior circumflex arteries. ${ }^{1,2}$ 
The ATA is a short arterial trunk originating from the second part of the AA. Its initial segment is covered by the $\mathrm{m}$. pectoralis minor, and it bypasses the medial border of the muscle. It pierces the clavipectoral fascia, then it splits into four branches according to the classical description: (1) the pectoral branch (RP) - generally the largest, traveling between the two pectoral muscles and providing their blood supply; (2) the acromial branch (RA), which contributes to the periacromial arterial network; (3) the clavicular branch (RC), which supplies the subscapular muscle and the sternoclavicular joint; and (4) the deltoid branch ( $\mathrm{RD}$ ), which supplies the $\mathrm{m}$. pectoralis major and parts of the deltoid. The RD and RA frequently originate from a common trunk. ${ }^{1-3}$

Variations of origin and branching pattern of the ATA are frequent. The vessel is the main source of blood supply for the skin of the anterior deltoid region and the anterosuperior chest wall. ${ }^{1,3}$ Certain areas of these regions are used as donors in clinical practice for reconstruction surgeries of the head and neck, as well as radical mastectomies. ${ }^{4-9}$ In case of injuries of the anterior chest wall, the AA and its branches may also be involved, which may also require surgical intervention. ${ }^{3-7}$

Considering the clinical significance, aside of the classical description of AA branches, familiarity with different

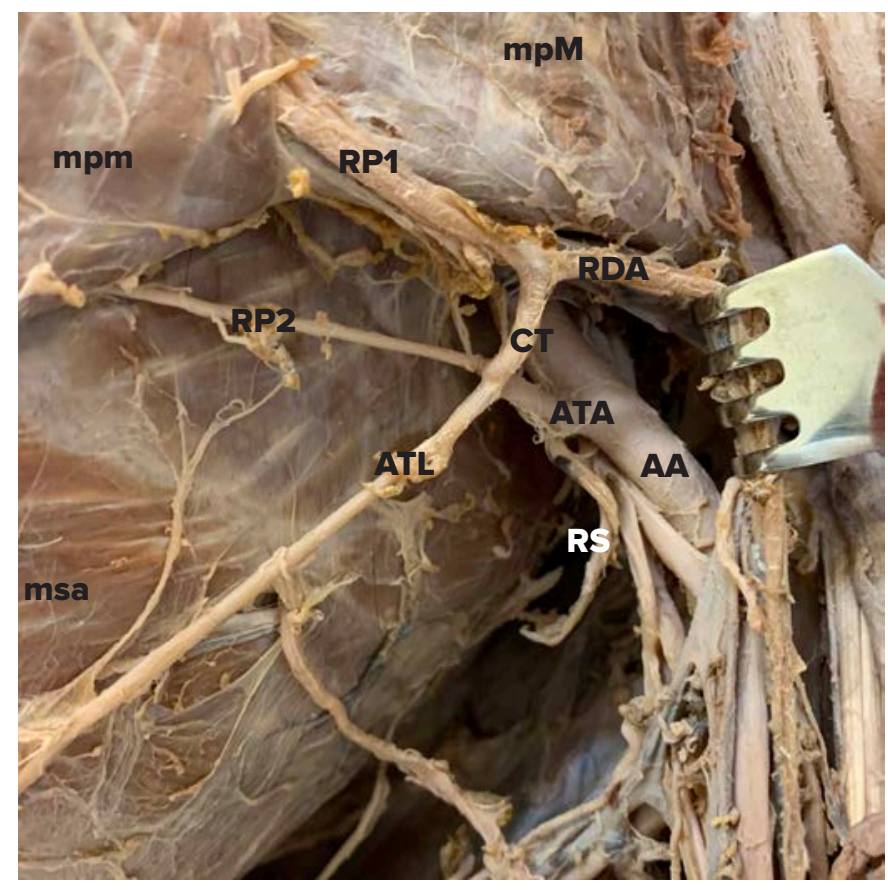

FIGURE 1. Origin and branches of a. thoracoacromialis. AA - a. axillaris; ATA - a. thoracoacromialis; RS - r. subscapularis; ATL - a. thoracica lateralis; CT - common trunk; RP1, RP2 - rr. pectorales; $\mathrm{RDA}$ - r. deltoido-acromialis; $\mathrm{mpm}-\mathrm{m}$. pectoralis minor; $\mathrm{mpM}-\mathrm{m}$. pectoralis major; $\mathrm{msa}-\mathrm{m}$. serratus anterior variations is also important. Lack of knowledge can lead to difficulties for plastic surgery, orthopedic surgery, and vascular surgery professionals during procedures involving this area. ${ }^{4-7}$

\section{CASE PRESENTATION}

We performed dissection of a formalin-fixed male body at the Department of Anatomy and Embryology of the "George Emil Palade" University of Medicine, Pharmacy, Science and Technology of Târgu Mureş, Romania. The study was approved by the ethics committee of the institution.

According to the classical description, the ATA originates from the second part of the AA, but in our case its branching pattern showed an unusual variation (Figures 1 and 2).

After cutting and pulling aside the $\mathrm{m}$. pectoralis minor, it was visible that right after the ATA branched off, it provided a posterior branch (r. subscapularis, RS) that coursed in the direction of $\mathrm{m}$. subscapularis. After a short distance, the ATA trifurcated into the following branches: a common trunk (CT), a pectoral branch (RP2), and ATL.

The common trunk of the thoracoacromial artery coursed in the anterior direction, and after a few centimeters it split into a pectoral branch (RP1) and a deltoid-acromial branch (RDA). The RP1 corresponded to the classical course of r. pectoralis, while the RDA was oriented towards the acromion, where it ended with small branches. The RP2 turned out to be an unusually well-developed acces-

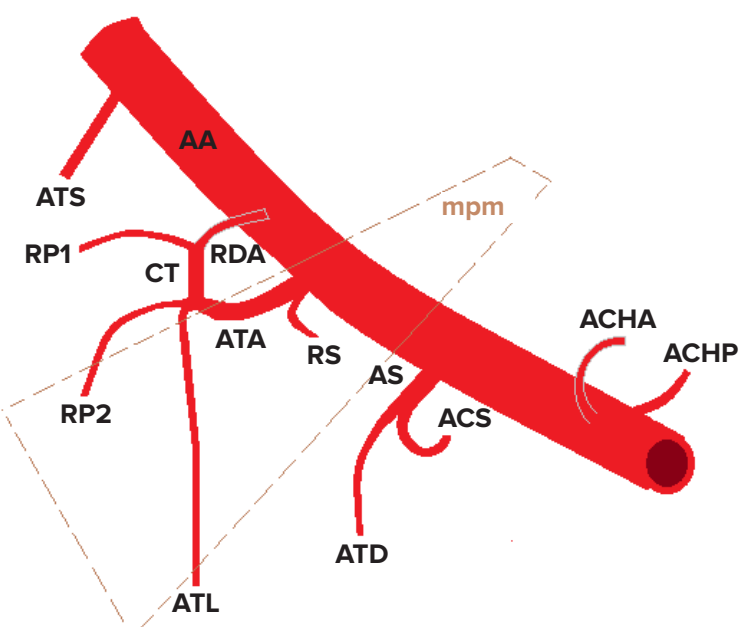

FIGURE 2. Arteria axillaris and its branches, demonstrating the anatomical variation. AA - a. axillaris; ATA - a. thoracoacromialis; RS r. subscapularis; $A T L$ - a. thoracica lateralis; $C T$ - common trunk; RP1, RP2 - Rr. pectorales; RDA - r. deltoido-acromialis; ATS - a. thoracica superior; AS - a. subscapularis; ACS - a. cirfcumflexa scapulae; ATD - a. thoracodorsalis; ACHA - a. circumflexa humeri anterior; ACHP a. circumflexa humeri posterior; $\mathrm{mpm}-\mathrm{m}$. pectoralis minor 


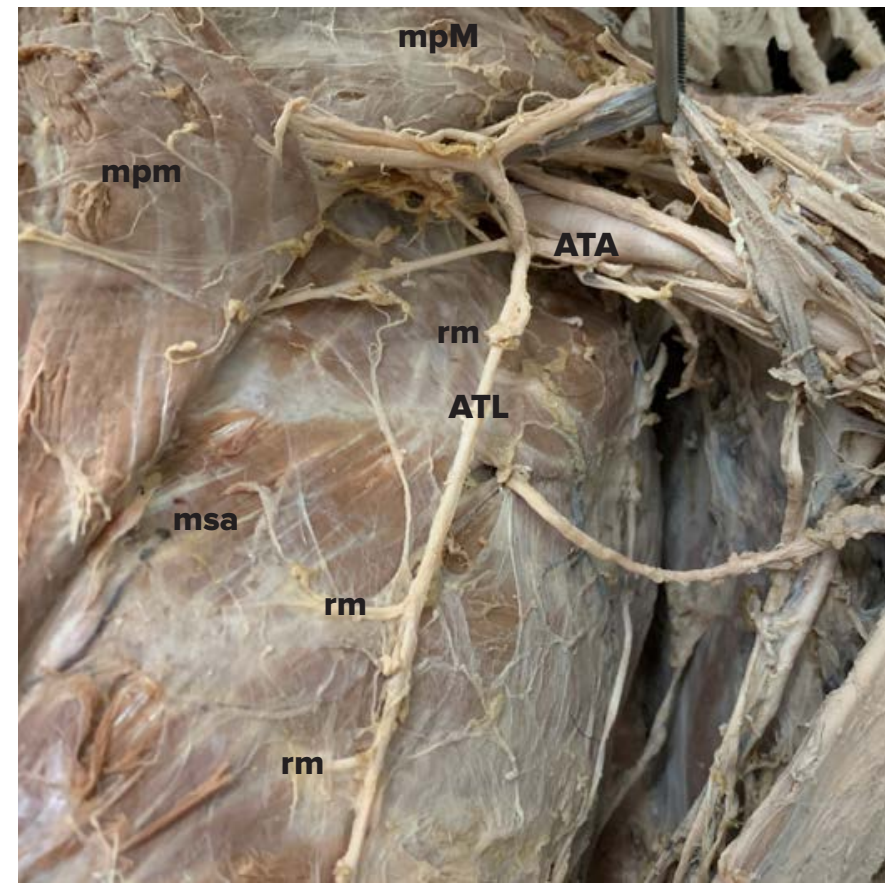

FIGURE 3. Origin of a. thoracica lateralis from a. thoracoacromialis. ATA - a. thoracoacromialis; ATL - a. thoracica lateralis; rm - rami musculares; $\mathrm{mpm}-\mathrm{m}$. pectoralis minor; $\mathrm{mpM}-\mathrm{m}$. pectoralis major; $\mathrm{msa}-\mathrm{m}$. serratus anterior

sory branch, which advanced between the $\mathrm{m}$. pectoralis minor and $\mathrm{m}$. serratus anterior, and provided small branches to supply these (Figure 1). The ATL coursed on the chest wall along the anterior axillary line and provided muscular branches $(\mathrm{rm})$ for the $\mathrm{m}$. serratus anterior and $\mathrm{m}$. pectoralis major (Figure 3). In the presented case, the clavicular branch of the ATA was missing. The rest of the branches of the AA corresponded to the classical description (Figure 4).

\section{DISCUSSIONS}

In our case, the ATA provided its first branch (RS) right after it detached from the AA. This first branch coursed initially in the posteroinferior direction between $\mathrm{m}$. subscapularis and the chest wall, then provided blood supply to the inferior part of $\mathrm{m}$. subscapularis. After detachment of the RS, the ATA had a 2 to $3 \mathrm{~cm}$ segment and trifurcated into a CT, RP2, and the ATL. A CT described by many studies ${ }^{10-12}$ was also present in our case, but it differed from the variants reported so far, considering that it split into a RP1 and RDA. There were two pectoral branches in our case: the origin of the RP2 was classical, but its course differed from that of the classically described ${ }^{1-3}$ pectoral branch, as it passed behind the $\mathrm{m}$. pectoralis minor, while the course of the RP1 was standard, but its origin was different. RC of the ATA was not present in our case. Absence of the cla-

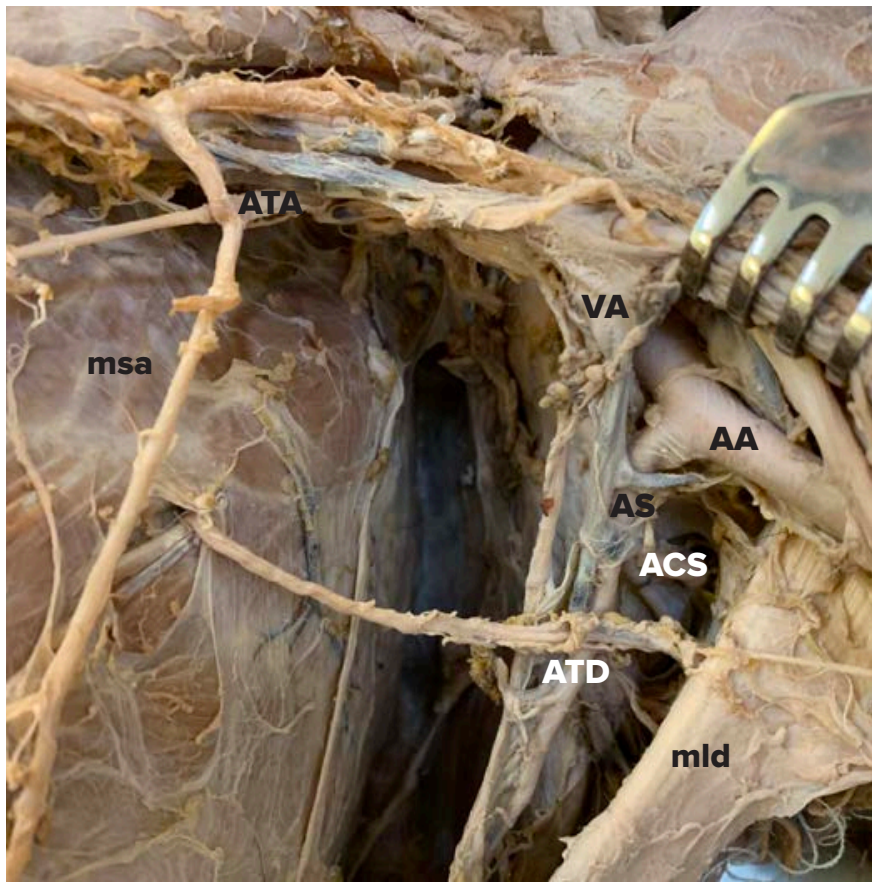

FIGURE 4. Origin and branches of a. thoracoacromialis and a. subscapularis. AA - a. axillaris; ATA - a. thoracoacromialis; AS - a. subscapularis; ACS - a. circumflexa scapulae; ATD - a. thoracodorsalis

vicular branch has been reported by several authors. $3,10,13$

In a dissection study of 89 cadavers, Huelke found the origin of the ATA from the second part of the AA in $2 / 3$ of the cases, and in $1 / 3$ of the cases it originated from the AA medial to the tendon of the m. pectoralis minor. The ATA was most frequently the medial branch of the second part of the AA. ${ }^{14}$ In our case, the ATA corresponded to the classical description, ${ }^{1,2}$ and it was the medial branch of the second part of the AA. Right after its detachment, the ATA provided a posteriorly oriented artery (RS), and then, after flanking the medial margin of the $\mathrm{m}$. pectoralis minor, it trifurcated.

Multiple studies report numerous branching patterns of the ATA. Nyemb et al. observed the presence of the deltoid and pectoral branches, but the acromial branch was missing in almost $50 \%$ of the cadavers, while the clavicular artery was missing in more than one-third of the cadavers. In most of the cases, the ATA subsequently separated into 2 to 4 branches. ${ }^{13}$

According to Pandey and Shukla, branching of the ATA and the origin of the branches are highly variable, but these variants can be classified into three groups. The first group comprises the separate deltoid-acromial and clavipectoral subtrunks that arise directly from the second part of the AA; the common thoracoacromial trunk is missing in these cases. In case of the second group variants, the clavicular branch originates separately from the second part 
of the AA, and a thoracoacromial trunk is also present and will subsequently trifurcate. In case of the third group, all four classical branches originate directly from the second part of the AA. ${ }^{15}$

Park et al. categorized the RP according to its origin from the ATA: type I (79\%) - the RP is a direct branch of the ATA; type II - the RP originates from the medial pedicle of the ATA; and type III - the RP originates from the lateral pedicle of the ATA. ${ }^{6}$

In a study by Astik et al., the ATA was missing in $8.8 \%$ of the cases, and the four classical branches of the ATA originated directly from the second part of the AA. In $5 \%$ of the dissected limbs, the ATA divided into two subtrunks (deltoid-acromial and clavipectoral), which on their turn split up into RD and RA, and RC and RP, respectively. In $3.7 \%$ of the cases, the ATA or its branches were missing completely. ${ }^{10}$

Geddes et al. found that the ATA originated from the AA as a single branch in all 20 limbs they had studied. In $60 \%$ of cases they observed secondary trunks. The RD was always a direct branch of the ATA, and it provided the acromial artery in $90 \%$ of the cases. The $\mathrm{RC}$ was the most variable: it originated from the ATA in $66 \%$ of the cases, from the RP in $24 \%$, and from the RD in $10 \%$ of the cases. Numerous and variable anastomoses can develop between the different branches. ${ }^{7}$

In a study by Loukas et al. involving a large number of cases (840 limbs), the ATL displayed high morphological variability in $96.7 \%$ of the cases. These variants were included in six categories. According to the authors, the most frequent variant was the ATL originating from the ATA $(67.7 \%)$, followed by the ATL originating from the AA (17\%), while in $<5 \%$ of the cases it originated from the ATD or the AS. Multiple ATLs have been described, but complete absence of the ATL has also been reported. ${ }^{16}$

According to the studies of Pandey and Shukla (India) ${ }^{15}$ and DeGaris and Swartley (USA) ${ }^{17}$, both involving a large number of cases, the ATL was reported most frequently as a branch of the ATA. Nevertheless, Lee et al. (South Korea, 189 cases) found the ATL to be a direct branch of the AA in $69.2 \%$ of the cases, ${ }^{18}$ which is in accordance with previous Korean ${ }^{19}$ and Japanese ${ }^{20}$ results. Contradictory results regarding the variations of the ATL suggest differences related to race.18 Rarely, the ATL may be a branch of the AS. ${ }^{21,22}$

In our case, the ATL was a branch of the ATA, which is in accordance with the work of Loukas et al. ${ }^{16}$ and DeGaris and Swartley ${ }^{17}$, who also state that the ATL may frequently be the branch of the ATA. We also describe the muscular branches of the ATL for the pectoral muscles and the m. serratus anterior, which corresponds to the classical reports. ${ }^{1,2}$

\section{CONCLUSIONS}

Numerous anatomical variations of the thoracoacromial artery have been reported, especially regarding its branching pattern. Thorough knowledge of the most frequent variants is important, but the possible occurrence of the less frequent or unknown variants should also be considered during surgical procedures in a given anatomical region. Our case study describes a variation of the thoracoacromial artery that has not been reported so far.

\section{CONFLICT OF INTEREST}

Nothing to declare.

\section{REFERENCES}

1. Standring S, Gray H. Grays Anatomy: the Anatomical Basis of Clinical Practice. Philadelphia: Elsevier, 2016

2. Paulsen F, Waschke J. Sobotta: Az ember anatómiájának atlasza. 23-ik kiadás. Budapest: Medicina könyvkiadó, 2013.

3. Tubbs RS, Shoja MM, Loukas m. Bergman's Comprehensive Encyclopedia of Human Anatomic Variation. New Jersey: John Wiley \& Sons, 2016.

4. Kanaka S, Eluru RT, Basha MA, Somasekhar R, Kanchanalatha G, Haniman $\mathrm{KS}$. Frequency of Variations in Axillary Artery Branches and its Surgical Importance. Int J Sci Stud. 2015;3:1-4.

5. Zhang $Y X$, Yongjie H, Messmer $\mathrm{C}$, et al. Thoracoacromial Artery Perforator Flap. Plastic and Reconstructive Surgery. 2013;131:759e-770e.

6. Park HD, Min YS, Kwak HH, et al. Anatomical study concerning the origin and course of the pectoral branch of the thoracoacromial trunk for the pectoralis major flap. Surg Radiol Anat. 2004;26:428-432.

7. Geddes CR. An assessment of the anatomical basis of the thoracoacromial artery perforator flap. Plastic Surgery. 2003;11:23-27.

8. Basaran K, Ucar A, Guven E, Arinci A, Yazar M, Kuvat SV. Ultrasonographically determined pedicled breast reduction in severe gigantomastia. Plast Reconstr Surg. 2011;128:252-259

9. Ogawa T, Hanamura N, Yamashita M, Kimura H, Kashikura Y. BreastVolume Displacement Using an Extended Glandular Flap for Small Dense Breasts. Plastic Surgery International. 2011;2011:1-7.

10. Astik R, Dave $U$. Variations in branching pattern of the axillary artery: a study in 40 human cadavers. Jornal Vascular Brasileiro. 2012;11:12-17.

11. Chakraborty P, Sarkar A. An Anatomical Study Of Variations In The Branching Pattern Of Axillary Artery And Its Clinical Significance. International Journal of Anatomy and Research. 2019;7:6934-6938.

12. Pant KM, Hasan S, Sarangdhar, Zaidi HH. Variation in branching pattern of the axillary artery - a case report. Int J Anat Var (IJAV). 2013:6:47-48.

13. Nyemb PMM, Fontaine C, Demondion X, et al. Anatomical variations of the trunk of origin and terminal branches of the thoraco-acromial artery. MOJ Anat Physiol. 2018;5:57-61.

14. Huelke DF. Variation in the origins of the branches of the axillary artery. The Anatomical Record. 1959;135:33-41.

15. Pandey SK, Shukla VK. Anatomical variation in origin and course of the thoracoacromial trunk and its branches. Nepal Med Coll J. 2004;6:88-91.

16. Loukas M, Plessis MD, Owens DG, et al. The lateral thoracic artery revisited. Surgical and Radiologic Anatomy. 2013;36:543-549.

17. DeGaris CF, Swartley WB. The axillary artery in white and negro stocks American Journal of Anatomy. 1928;41:353-397.

18. Lee $\mathrm{H}$, Kim H-T, Lee J-H, Choi I-J. Low frequency of the lateral thoracic artery originating from the thoracoacromial artery. Surgical and Radiologic Anatomy. 2014;37:319-320.

19. Kang ES. Study on the Branches of Axillary Arteries of Korean Adult. Journal of the Korean Orthopaedic Association. 1967;2:71.

20. Adachi B. Das arteriensystem der Japaner, vol 1. Kyoto: Verlag der Kaiserlich-Japanischen Universität zu Kyoto, 1928.

21. Abdalla MA. Morphometric and analytic study of axillary artery course and its branches. Tikrit Med J. 2007;13:132-138.

22. Sipos TC, Dénes L, Brînzaniuc K, Szántó A, Pávai Z, Pap Zs. Variation of the origin of the lateral thoracic artery. Case report. Revista Română de Anatomie funcțională şi clinică, macro-şi microscopică şi de Antropologie. 2018;4:299-302. 